\title{
Frameworks to enhance inclusion in physics education: everyone must participate
}

\author{
Joshua C. Collins, EdD \\ Associate Professor of Human Resource Development, University of Minnesota-Twin Cities, \\ 178 Pilsbury Dr SE, Minneapolis, MN, 55455
}

The essential work of cultivating inclusive environments in organizations, communities, and society too often falls to those who are themselves members of marginalized and underrepresented groups. This can be especially true in masculinized and male-dominated professions, where the conditions of work and productivity and the valuation of knowledge and skills has historically been defined by those with a combination of dominant social identities, such as being white, being male, being heterosexual, and being cisgender. A good example of such a profession is that of physics and physics education. More recently, there have been calls to move the work of inclusion from the margins of such environments more to the center. Such a movement could prove important in the process of recreating and positioning the work of inclusion as the obligation of everyone, rather than the responsibility of the marginalized and underrepresented. The purpose of this plenary paper is to discuss how bystander intervention and ally development frameworks can be utilized in physics education to promote and sustain greater inclusion for marginalized and underrepresented groups by framing inclusion as the obligation and responsibility of everyone. 


\section{INTRODUCTION}

The purpose of this plenary paper is to discuss how bystander intervention and ally development frameworks can be utilized in physics education to promote and sustain greater inclusion for marginalized and underrepresented groups by framing inclusion as the obligation and responsibility of everyone. To properly situate this work in the context of physics and physics education, I ask the reader to consider the following question: How do you see your individual role in addressing oppression, discrimination, and other systems of marginalization which impact minority and underrepresented groups? Let your answer to this question guide you as you read the rest of this paper.

Byrd defined social injustice as "the repression of a person's individual and civil rights which in the process could hinder their capacity to achieve full potential to learn and perform" [1]. Byrd added: "A social injustice can be either an overt or covert act or behaviour that is intended to demean or degrade by calling attention to the person's social identity, or to emphasize and remind the person of their marginalized location in society" [1]. Finally, Byrd defined social justice as "a democratic, participatory, inclusive process and vision" [1] which demands diversity, equity, and inclusion of all.

We must invite everyone to participate in the work of inclusion. While many people might desire to be inclusive, many also lack the necessary skills to actually forge inclusive environments and structures. Fortunately, there are two useful frameworks, bystander intervention and ally development, for engaging in this process [2]. First, bystander intervention, which is a method of training people to recognize injustice and to intervene to stop it, emphasizes behaviors which can impact the ability of groups of people to create and sustain inclusive environments. Second, ally development, which advances the recognition of injustice and commitment to fighting for the "other," emphasizes the necessary attitudes which inform and inspire inclusivity.

\section{PROMOTING ORGANIZATIONAL JUSTICE IN PHYSICS EDUCATION}

A couple of years ago, I was a part of a large team looking at addressing sexual misconduct on our campus. We had a few high profile cases of misconduct coming out of our athletic department and the president of the university at the time decided to make it a priority. As a part of my work, I had conversations with faculty and staff in a variety of roles across campus. One conversation in particular sticks out in my mind. It was with a prominent professor in a STEM field. In this conversation, this person-a man-ended up revealing to me that his approach to preventing sexual misconduct in his research lab would be, "to wait until Me Too blows over before hiring any more women." His statement resonated with me because it reflected a popular attitude which is that the onus for creating more social justice and more inclusion is on those who are impacted by injustice. This attitude can be especially pervasive in masculinized industries [3] such as physics and physics education.

However, no one can just sit on the sidelines and not also label themselves a conspirator for injustice. If you do not want to carry that label, you must get involved. Everyone must participate. One way to invite more people into this work is to promote an understanding of organizational justice [4]. Organizational justice has developed as a framework for contextualizing social justice as an imperative within organizations. Organizational justice is comprised of four components: distributive justice, procedural justice, interpersonal justice, and informational justice. Organizational justice provides context for understanding how bystander intervention and ally development-as initiatives which generally have a focus on individual development - contribute to creating larger systems that are centered on social justice and inclusion. Distributive justice [4] is conceptualized as the fairness associated with decision outcomes and distribution of resources. In tending to distributive justice in physics education, one question that could be asked is [5]: What is the range of voices and perspectives that are being included in this change, policy, educational effort, research, etc.? Procedural justice [4] is defined as the fairness of the processes that lead to outcomes. In tending to procedural justice in physics education, one question that could be asked is [5]: Who is in or has the power? How will power be addressed in order to foster more inclusion across multiple dimensions of diversity? Interpersonal justice [4] means treating other people with dignity and respect. In tending to interpersonal justice in physics education, one question that could be asked is [5]: Whose interests are being considered and served in through this decision, policy, research, etc.? Finally, Informational justice [4] is focused on the fairness of the ways that information is communicated and dispersed in an organizational context. In tending to informational justice in physics education, one question that could be asked is [5]: How much and what type of attention is being given to opportunities for different individuals and groups to be heard?

\section{BYSTANDER INTERVENTION}

Bystander intervention is a method of training people to recognize risky or dangerous situations (including abuse, assault, harassment, and discrimination) and to intervene [2]. Bystander intervention is useful as a tool because it promotes clear and decisive action when faced with or witnessing an injustice. However, there are some important limitations when approaching social injustice and a lack of inclusion through the mechanism of bystander intervention alone. First, much of the work of intervening in injustice still falls to marginalized groups. There is an abundance of evidence supporting the idea that power and privilege are important 
factors in a person's ability to intervene [6], and yet, who do we primarily see marching in the streets when an innocent Black life is taken at the hands of the police? Who is speaking up in that important meeting regarding diversity in your department? A second barrier to effective bystander intervention is that not all bystanders have pure intentions [7]. Bystander intervention holds the position that we are all bystanders of injustice and discrimination. We are all capable of seeing it happening. But not only are we faced with the choice of whether or not to do something, some bystanders may active agree with the actions of a perpetrator. In these instances, it becomes the responsibility of other bystanders, especially those with privileged identities, to intervene on behalf of targets. A third barrier to bystander intervention is often organizational or institutional support [8], or a lack of willingness of organizations and institutions to invest in disrupting behaviors often over fear of political fallout from that decision. Leaders must begin to prioritize the wellbeing of the most vulnerable in order to advance inclusion. Finally, bystander intervention promotes the idea that bystanders must also assess the risks to themselves in a situation before intervening [9]. This can be a limitation to creating more justice through the mechanism of bystander intervention because it promotes the idea that intervening in injustice does not pose risk to us as individuals, when of course it might. However, the more people who are involved in the disruption of injustice, the less likely any one party is to suffer the consequences of intervention. We need allies.

\section{ALLY DEVELOPMENT}

According to higher education scholar Keith Edwards, allies are those who strive to "reform or dismantle systems of oppression" [10]. This definition implies that allies can be anyone. Ideally, allies are people who are willing to stand with minority groups in solidarity as they face systems of marginalization. Most ally development models and programs, unlike bystander intervention, do not take risk into account at all. This means that people often identify as allies without ever thinking about what that does or should actually mean. A lot of people want to be allies but they also want to be free of the consequences which are sometimes associated with supporting social justice. Other barriers to ally development include that development is usually spurred and fueled by interaction with people who have experienced marginalization [11]. This means that some people who never diversify their social circles may be more easily removed from the experience of marginalization and therefore less likely to engage. There is also a lack of knowledge about communities that need support or what kind of support is actually needed [12]. This is where collective action is necessary and helpful, in that we can fill in each other's gaps in knowledge by building networks of allies who are ready to educate and to take action. A final and most important barrier to ally development is inconsistency in the application of ally identity. There is a wide range of ways people think about being an ally. Not all of them are equally effective. Understanding and working through the self-interest that may sometimes be involved with a person's allyship is, therefore, a crucial first step.

\section{RECOMMENDATIONS: WHAT YOU CAN DO}

I end this paper with a few recommendations of what you can do, today, to begin actively promoting inclusion in physics and physics education. First, engage in selfreflection. Ask yourself: What am I doing to actively promote social justice and inclusion? The answers may surprise you. Second, be a bystander who intervenes. When you see a wrong, work to make it right, and bring others along with you. Third, be a true ally. Ask yourself: Is my vision of social justice and inclusion fit for all vulnerable people, even the ones that I do not understand? It is easy to include those who we understand. It is more difficult, and yet essential, to promote the inclusion of differences we do not yet fully understand but respect nonetheless. Fourth, establish a trusted group of co-conspirators for inclusion. Meet regularly and discuss your advocacy efforts the same way that you would meet and discuss anything else of importance. Finally, do not apologize for setting boundaries or being firm on these issues. Strength of conviction is a key factor in inspiring others to join the effort for more inclusion.
[1] M. Y. Byrd, Human Resource Development International 21, 1 (2018).

[2] J. C. Collins, P. Zhang, and S. Sisco, Human Resource Development Review (2021, forthcoming).

[3] J. C. Collins, Human Resource Development Review 14, 4 (2015).

[4] J. A. Colquitt, Organizational Justice. In The Oxford Handbook of Organizational Psychology, (Oxford University Press, 2012).

[5] B. Ferdman, OD Practitioner 46, 4 (2014).
[6] E. S. Focella, M. Bean, and J. Stone, Social and Personality Psychology Compass 9, 2 (2015).

[7] M. Paull, M. Omari, and P. Standen, Asia Pacific Journal of Human Resources 50, 3 (2012).

[8] G. Lee and W. J. Lee, Computers in Human Behavior 26, 6 (2010).

[9] K. Yule and J. Grych, Journal of Interpersonal Violence 35, 15$16(2020)$.

[10] K. E. Edwards, NASPA Journal 43, 4 (2006). 
[11] S. S. Rostosky, W. W. Black, E. D. B. Riggle, and D. Rosenkrantz, American Journal of Orthopsychiatry 85, 4 (2015).

[12] I. E. Sabat, L. R. Martinez, and J. L. Wessel, Industrial and Organizational Psychology: Perspectives on Science and Practice 6, 4 (2013). 